\title{
OS MITOS AFRICANOS E A LÍRICA DE PROTESTO NA POESIA CONTEMPORÂNEA DE WALDO MOTTA
}

\section{THE AFRICAN MYTHS AND THE LYRIC OF PROTEST IN THE CONTEMPORARY POETRY OF WALDO MOTTA}

\author{
Ricardo Alves dos SANTOS ${ }^{38}$ \\ Kênia Maria de Almeida PEREIRA ${ }^{39}$
}

\begin{abstract}
RESUMO: Este artigo pretende avaliar as influências dos mitos africanos na lírica de protesto do poeta contemporâneo Waldo Motta. As articulações teóricas sobre o mito estarão centralizadas nas formulações de Mircea Eliade, bem como estudiosos dos mitos africanos: Roger Bastide, Pierre Verger e Reginaldo Prandi. O objetivo desta reflexão é atestar o valor do mito para a construção do discurso lírico de protesto em Bundo e outros poemas (1996), de Waldo Motta.
\end{abstract}

PALAVRAS-CHAVE: Poesia brasileira contemporânea; Mitos africanos; Lírica de protesto.

ABSTRACT: This article aims to assess the influencies of African myths in the lyric of protest of the contemporary poet Waldo Motta. The academical articulations about the myth are concentrated on the formulations of Mircea Eliade, as well as on African myths scholars: Roger Bastide, Pierre Verger and Reginaldo Prandi. The purpose of this reflection is to attest the myth value for the construction of the lyric discourse of protest in Bundo e outros poemas (1996) by Waldo Motta.

KEYWORDS: Brazilian contemporary poetry; African myths; Lyric of protest.

A contemporaneidade marca incessantemente um percurso contraditório e dilemático da existência humana. As relações que o indivíduo trava com o mundo e com ele mesmo evidenciam a necessidade de vencer as barreiras que o homem comum

\footnotetext{
${ }^{38}$ Mestrando. Programa de Pós-Graduação em Teoria Literária - ILEEL - Universidade Federal de Uberlândia (UFU) - Uberlândia - MG - Brasil - CEP 38408-100 - ricardo.ia.alves@gmail.com

${ }^{39}$ Orientadora. Programa de Pós-Graduação em Teoria Literária - ILEEL - Universidade Federal de Uberlândia (UFU) - Uberlândia - MG - Brasil - CEP 38408-100 - kenia@triang.com.br
} 
encontra ao se deparar com a solidão, com a exclusão e com a necessidade de se realizar em uma esfera social ou individual.

Nesta perspectiva, o mito parece construir um diálogo coerente para enfrentar as discrepâncias e as irrealizações comuns em tempos corrompidos por uma verdade científica que nem sempre agrega valor significativo à experiência subjetiva. $\mathrm{O}$ sujeito está imerso nas obscuridades de seu tempo e os elementos míticos colaborariam para elevar a existência humana na medida em que manifestam um caráter sagrado, como assinala Mircea Eliade (1992a) em sua obra Mito e realidade. Assim, promoveriam uma peculiar maneira de o homem sair de uma realidade conduzida pelo caráter lógicoracional para caminhar por vias míticas, onde a conduta humana ganha "significação e valor".

O mito, por guardar um valor sacralizador e religioso, revela-nos o quanto ele é importante para a humanidade, já que seu caráter misterioso e metafísico se porta como maneira de questionar a própria realidade e, a partir disto, fortalecer o que nem sempre a condição social, ou melhor, o ser social recebe dos seus iguais. A religiosidade como instância mítica permite e favorece um encontro com um outro que também não tem respostas para algumas perguntas que resistem na contemporaneidade: Quem sou eu? Qual é a origem humana?

As tentativas de respostas ou as formas para lidar com estas reflexões tipicamente existenciais podem ter explicações em diversas áreas do conhecimento humano; a saída mítica é percorrida pelo poeta capixaba Waldo Motta em Bundo e outros poemas (1996), na qual o valor mitopoético é realizado com apuro, objetivando grifar a exclusão social. Neste artigo, buscaremos mostrar como os elementos sagrados da mitologia africana, especificamente os mitos de Exu e de Ogun, corroboram para um discurso lírico em diálogo com posições sociais que ainda excluem e discriminam. $\mathrm{O}$ mito africano é (re)construído por um sujeito lírico que almeja questionar sobre a falta de tolerância que assombra o homem pós-moderno.

Para Levi Strauss (1978, p.33), "na mitologia do mundo inteiro, há deidades ou personagens sobrenaturais que desempenham o papel de intermediários entre os poderes de cima e a Humanidade em baixo". Dessa forma, o universo mitológico cria uma atmosfera relacional entre o plano concreto, material e o plano divino, idealizador, criativo da atividade sócio-cultural humana.

"Os poderes de cima" são transmitidos por entidades sobrenaturais que não apresentam uma materialidade científica e histórica, mas instauram uma maneira 
exemplar de o homem buscar ideais de comportamento sociais mais dignos para a concretude das ações e atitudes que operam na teia social.

O elemento sagrado, que envolve os mitos, pode salientar um direcionamento para as prerrogativas que insistem no presente humano. Cotidianamente, deparamo-nos com várias situações em que a ideia de pós-moderno e todas as implicações desta condição - a igualdade, a democracia, o respeito ao outro, o desenvolvimento tecnológico, o individualismo - comprometem a realidade ao deformar os valores que poderiam reger uma sociedade mais justa e igualitária. Assim, o mito reproduz um retorno a ensinamentos e a ações que se consagraram ao longo da história humana.

Sabendo do aspecto fabuloso, inventivo e ficcional que envolve a definição do mito, Eliade (1992a) pontua que esta visão não é a verificada nos estudos que engendram os eruditos mitólogos da atualidade. Para eles o mito passa a ser compreendido em bases das sociedades arcaicas, nas quais esse "designa [...] 'uma história verdadeira' e, ademais, extremamente preciosa por seu caráter sagrado, exemplar e significativo" (ELIADE, 1992a, p. 7). O mito se manteria "vivo" nestas sociedades, já que forneceria "os modelos para a conduta humana, conferindo, por isso mesmo, significação e valor à existência" (ELIADE, 1992a, p.8).

A situação bem argumentada por Eliade leva-nos a reconhecer os mitos como "fenômenos humanos", "fenômenos de cultura", "criação do espírito". O mito revelanos um segredo, um mistério que mantém sua permanência no imaginário cultural de um povo; o entrelaçamento entre espírito e realidade atestaria seu valor religioso e sagrado.

O valor sagrado do mito e sua propriedade de poder ser interpretado e elaborado em diferentes perspectivas tornam-no matéria-prima para novos questionamentos sobre a condição humana. Este aspecto de reatualização do mito confirma sua capacidade de ser, alegoricamente, um instrumento de integração entre o homem e o Cosmo, em que o elemento religioso e mítico recebe novos contornos conforme a necessidade humana.

O homem moderno, imerso nas contradições do seu tempo, entrega-se ao sagrado em uma busca constante por respostas. O sujeito frente à realidade se lança em uma atmosfera metafísica para dar conta de si, unindo, num mesmo plano, o real e o imaginário e, assim, destaca sua gênese de homo religiosus verificada desde os primórdios. Segundo Eliade, em $O$ sagrado e o profano: 
Seja qual for o contexto em que se encontra, o homo religiosus acredita sempre que existe uma realidade absoluta, o sagrado, que transcende este mundo, que aqui se manifesta, santificando-o e tornando-o real. Crê, além disso, que a vida tem uma origem sagrada e que a existência humana atualiza todas as suas potencialidades na medida em que é religiosa, ou seja, participa da realidade. (ELIADE, 1992b, p. 97).

Por mais que a contemporaneidade seja marcada por um homem a-religioso, que crê ser o "único sujeito e agente da História", e abdica de qualquer situação de transcendência e, por conseguinte, de explicação mítica para sua existência, o homem areligioso de certa maneira descende do homo religiosus apontado por Eliade. O homem contemporâneo, marcadamente científico, carrega a herança de seus antepassados, que explicavam o mundo por vias míticas e sagradas, entretanto este negará qualquer relação de subserviência aos deuses mitológicos, construindo uma dessacralização dos valores que regem os elementos míticos ao esvaziá-los dos "significados religiosos".

Ao lidar com uma experiência sagrada e mítica, condição que funda o mundo, a religião passa a ser

[...] a solução exemplar de toda crise existencial, não apenas porque é indefinidamente repetível, mas também porque é considerada de origem transcendental e, portanto, valorizada como revelação recebida de um outro mundo, transumano. A solução religiosa não somente resolve a crise, mas, ao mesmo tempo, torna a existência 'aberta' a valores que não são contingentes nem particulares, permitindo assim ao homem ultrapassar as situações pessoais e, no fim das contas, alcançar o mundo do espírito. (ELIADE, 1992b, p. 97).

A crise mencionada por Eliade coaduna-se com a postura poética do poeta capixaba contemporâneo Waldo Motta que dialoga com o sagrado e profano para destacar sua condição presente. O mito na lírica de Motta permite ao eu poético transcender e encontrar um outro que também tem suas bases existenciais em elementos sacralizadores e religiosos.

Torna-se necessário, neste momento, discorrer sobre o escritor Waldo Motta e seu projeto literário. Waldo Motta é um poeta capixaba, negro e homossexual que, em um universo de estudos autônomos, buscou em sua poética um espaço por onde as 
dialéticas contemporâneas ${ }^{40}$ emergiriam, elucidando sua postura marginal em relação às várias segregações perenizadas pela sociedade atual.

A postura de Waldo Motta é assim destacada pelo poeta em seu artigo "Enrabando o capetinha ou o dia em que Eros se fodeu" (2000):

No prefácio do livro Bundo e outros poemas, publicado em 96 pela editora da Unicamp, informo que, a parir da metade dos anos 80, passei a questionar seriamente a homossexualidade e a sexualidade em geral, iniciando uma reviravolta em minha vida e em minha visão de mundo (MOTTA, 2000, p. 59).

A questão social e existencial do poeta insere-se em sua obra como uma "viagem de autoconhecimento". Na tentativa de entender a si e às contradições do mundo contemporâneo, Motta elege para seu labor artístico o diálogo com os mitos hebraicos e africanos, com a astrologia, os símbolos e a cabala para construir Bundo e outros poemas, um livro que, pelas palavras do próprio poeta, é "inspirado" no "livro dos inspirados" (Bíblia Cristã), portanto apresenta um discurso lírico versado com recursos sagrados.

Iumna Simon, no ensaio "Revelação e desencanto: a poesia de Waldo Motta" (2004), atesta o quanto a poética de Motta revela um diálogo com o seu tempo, incorporando uma sensibilidade não verificada na postura marginal do contexto das primeiras experiências do autor, período em que a poesia marginal no Brasil apresentava uma postura antiliterária. Desta forma, o universo lírico de Motta seria uma tentativa sensível de se posicionar em relação a sua realidade marginalizada (periférica). Por Iumna,

[...] a figura do marginal, do bandido, do indigente foi idealizada a ponto de ser esvaziada de sua concretude social e equiparada à nova sensibilidade poética. Retomando uma formulação feita em outro lugar, tal identificação mostrava que à miséria popular eram atribuídas as mesmas posturas que o poeta assumiu: 'a ignorância é curtida como anti-intelectualismo, a desclassificação social como transgressão pequeno-burguesa, a falta de perspectivas como negação do progresso. A desqualificação estilizada impõe seus pontos de vista e interpreta a outra, a social, à sua imagem e semelhança'. (SIMON, 2004, p. 210).

O tom profético e transgressor do poeta já é revelado no primeiro poema da obra Bundo e outros poemas, intitulado "Descobrimentos", no qual o sujeito lírico anuncia a

\footnotetext{
${ }^{40}$ As dialéticas contemporâneas serão tratadas a partir do enfoque de Giorgio Agamben, as quais perpassam o fato de o contemporâneo se caracterizar pela "singular relação com o próprio tempo, que adere a este, e ao mesmo tempo, dele toma distâncias" (AGAMBEN, 2009, p. 59).
} 
sua chegada de maneira, no mínimo, inquietante, já que se direciona aos "Gênios perversos, bestas solertes,/ hostes medonhas, greis infernais", sinalizando uma necessidade de protestar contra uma sociedade ainda "adormecida":

"Descobrimentos"

Aqui vou eu, bundo, pando, ó país que almejo e canto, terra desolada, bela adormecida, virgem por salvar!

Gênios perversos, bestas solertes, hostes medonhas, greis infernais, aqui vou eu, verbo em riste, arredai!

Hidras, quimeras, anfisbenas, lâmias, gorgonas, gárgulas, ogros, exus, anhangás, humbabas, abracadabra!

Eldorados, thules, surgas, agarthas, cimérias, hespérias, pasárgadas, cólquidas, xangrilás, cocanhas, saléns, guananiras, reinos miríficos, mundos arcanos, céus interditos, aqui estou eu!

Velocinos, tesouros, manás, elixires, graais, aqui eis!

(MOTTA, 1996, p. 21).

O eu-lírico, "bundo" e "pando", dirige-se, primeiramente, ao seu país, que almeja e canta, atestando também que sua "terra", "bela" e "virgem", está "adormecida" e "desolada" em relação ao que deseja proferir. Entretanto, a apóstrofe empregada pelo poeta na primeira estrofe do poema ganha contornos não apenas pessimistas: o país é “virgem por salvar". Esta esperança revela que o eu poético busca uma mudança, uma transformação na mentalidade das "bestas solertes", as quais exercem um poder de dominação e exclusão social, uma das temáticas trabalhadas na obra do poeta contemporâneo.

Para seu propósito provocador, serão convocadas entidades mitológicas que, de forma mais ou menos explícita, simbolizam o caráter diabólico e infernal da voz lírica, pela qual um discurso inflamado e de protesto idealiza mundos, "pasárgadas", "reinos miríficos". Aí “estou eu”, assim o poeta termina a quarta estrofe do poema, colocando-o 
em um espaço onde o maravilhoso, o mítico, o sobrenatural tecerão um confronto com ações pouco humanizadas da sociedade de hoje, criando um paraíso que destoa do universo de marginalização vivenciada em tempos atuais.

As várias enumerações verificadas no poema antecipam o quanto Motta se revela perseguidor das práticas que deixam sua pátria em "desolação". Assim, traz para seu labor poético o imperativo "arredai", suscitando uma voz que se impõe diante das perversidades e luta de maneira poética para encontrar os idílios reconfortantes (encadeados na $4^{\mathrm{a}}$ estrofe), a serem reconstruídos a partir dos "descobrimentos" que sua condição excludente lhe conferiu.

O emprego de "hidras, quimeras, exus" coloca o mítico e o místico em harmonia com seu protesto, já que estes seres serão convidados para as reivindicações do artista, aterrorizando as bases que fundam e reiteram as diferenças através de contrários, os quais não refletem o ímpar de cada cultura sem antes compará-lo à cultura dominante. Em outras palavras, o poeta capixaba deita o sagrado em raízes culturais e promove uma subversão dos valores que engendram a postura conservadora e tradicional.

A inspiração poética de Motta, a partir da leitura do poema "Descobrimentos", exemplifica a variedade de suas fontes, situação referendada pelo poeta:

O poema 'Descobrimentos', onde abusando das sinédoques, aproximo diferentes concepções do centro sagrado ou paradisíaco, nivelando assim as numerosas visões dessas plagas míticas, fabulosas, que aludem sempre ao mesmíssimo lugar: 'Eldorados, thules, surgas, agarthas,/ cimérias, hespérias, pasárgadas, cólquidas,/ xangrilás, cocanhas, saléns, guananiras,/ reinos miríficos, mundos arcanos,/ céus interditos, aqui estou eu!' (MOTTA, 2000, p. 61).

A poesia lírica nutre-se, pois, do universo mítico e místico para se refazer e se reconstruir a partir da fala ${ }^{41}$ destes universos, possibilitando incitar e, quem sabe, reconstruir laços mais humanos em nossa sociedade, já que o mito apresenta um eixo sacralizador que se orienta pelo espírito humano.

O destaque dado a "exu(s)" pelo eu poético logo no primeiro poema, "Descobrimentos", se intensifica na obra de Motta, sinalizando um diálogo arquetípico $^{42}$ com esse orixá/entidade sagrada da cultura africana:

\footnotetext{
${ }^{41} \mathrm{O}$ emprego desta palavra aqui vai ao encontro da teoria barthesiana desenvolvida no livro Mitologias (2001), na qual "o mito é uma fala", "é um sistema de comunicação", "é uma mensagem".

${ }^{42} \mathrm{O}$ conceito de arquétipo contemporâneo foi desenvolvido na teoria psicológica de Jung. Segundo Meletínski (1998), "os arquétipos junguianos [...] são antes imagens, personagens, papéis a serem desempenhados" (MELETÍNSKI, 1998, p. 22).
} 


\section{NO CU}

DE EXU

A LUZ

(MOTTA, 1996, p. 69).

Exu, no poema de Motta, aprisionaria o sentido de materialização do sagrado, alicerçado em uma cultura de origem negra ainda assombrada pelo discurso homogeneizante e, por que não, alienante do cristianismo. A palavra "cu", símbolo erótico, seria divinizado, teria "luz" com a entrada de "Exu".

Exu, segundo Roger Bastide em O candomblé da Bahia (2001), é considerado o último filho de Iemanjá, sendo o mais jovem dos 17 orixás que tiveram sua origem no "ventre incestuoso" da rainha do mar. "Os etnólogos que na África se interessaram pela figura de Exu ou por seus mitos o designam pelo termo trickster [...] parece um ser malicioso que se compraz em brincadeiras, em lograr tanto os deuses como os homens" (BASTIDE, 2001, p. 161).

A ideia associada de Exu a um trickster também é notada nos candomblés do Brasil. Por questões históricas, Exu tem conotações maliciosas e diabólicas, designando, muitas vezes, um “diabo cruel e malvado". Este valor do orixá Exu está intimamente relacionado ao fato de este ser utilizado/convocado em magias contra o branco escravizador, identificando-o "com o diabo dos cristãos, vendo nele o princípio do mal, o elemento demoníaco do universo" (BASTIDE, 2001, p. 162).

Mas Exu é também o orixá que apresenta uma essência mais próxima dos homens. Segundo Barcellos, "Exu é o nosso interior, é a nossa intimidade, o nosso poder de ser bom ou mau, de acordo com a nossa vontade. Exu é o ponto mais obscuro do ser humano e é, ao mesmo tempo, aquilo que existe de mais óbvio e claro" (BARCELLOS, 2002, p. 51).

O aspecto dilemático que o arquétipo de Exu promove é sinalizado no poema de Motta. "No cu / de Exu" há "luz", o aspecto diabólico de Exu é desconstruído pela ideia de luminosidade, paz e paraíso, também ancorada nesse orixá. O elemento sagrado reveste-se de um valor diferente daquele que a maioria consagrou como sendo o estereótipo do diabo cristão. O poema dá um novo lugar para o sagrado da cultura africana.

Barcelos, ao destacar que "Exu é o nosso interior", dialoga de certa maneira com a postura do sujeito lírico de Motta, já que o "cu" metonimicamente pode representar a 
interioridade humana que busca a luz como elemento de redenção e de esclarecimento existencial.

Outro aspecto importante desta entidade africana é descrito por Reginaldo Prandi em sua obra Mitologia dos orixás (2001):

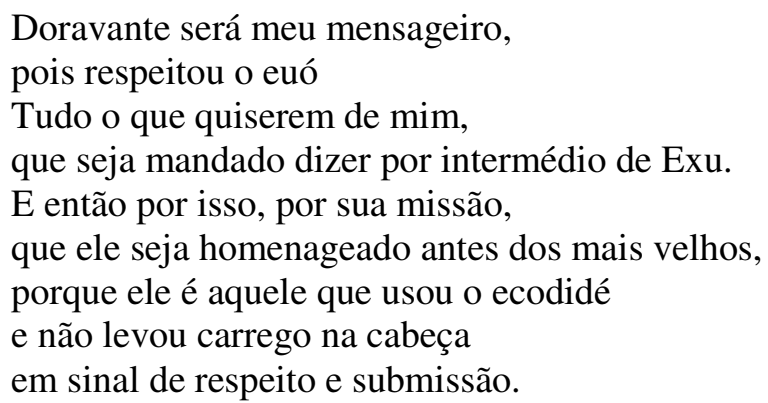

(PRANDI, 2001, p. 43).

Como mensageiro de Olodumare, Exu passa ser o mensageiro dos homens. A partir de Exu, nossos desejos são atendidos e consagrados. O respeito e a submissão de Exu conferiram-lhe o estatuto de ser reverenciado antes dos orixás mais velhos. Todo culto africano, assim, "começa obrigatoriamente por uma homenagem a Exu" (BASTIDE, 2001, p. 167).

Assim, o poema de Motta reconstrói o mito de Exu e é marca de onde o discurso poético busca sua referencialidade: a cultura do negro insere-se na lírica de protesto de Motta. O sujeito lírico integra-se ao arquétipo de Exu para proferir uma mensagem ainda excluída no percurso histórico do negro brasileiro.

Nota-se que no curto poema de Motta o universo mítico abre uma instância para se repensar qual é o valor da cultura e do negro, corroborando para destacar a diferença no local de onde ela emerge enquanto processo cultural. A valorização cultural, muitas vezes, é revestida por um tom ameaçador e crítico, como ocorre no poema "Preceituário para racistas com receita de rebuçado e contra-receita de angu":

\section{PRECEITUÁRIO PARA RACISTAS COM RECEITA DE REBUÇADO E CONTRA-RECEITA DE ANGU}

Ogun pá

Lele pá

Ogun pá

Koropá...

- canto afro

Quem atiça o tição 
sabe do risco que corre, sabe que ao bulir com fogo é arriscado provocar a ebulição de quanto há tanto vem nos enchendo o caldeirão da paciência.

Portanto, todo cuidado é pouco quando se atiça o tição, quando se bole com o fogo, pelo risco de transformar rebuçado em ração para a racinha ordinária dos racistas.

Quem atiça o tição sabe muito bem do risco de atear fogo em tudo, sabe que, ao provocar a ebulição da massa é arriscado explodir $\mathrm{o}$ angu em todo o mundo.

sabe que, súbito, tudo, tudo pode ficar preto \& vermelho, como queiram, num belíssimo incêndio inusitado.

Pois quem atiça o tição atira mais lenha aos sonhos que nos abrasam, braseiro oculto sob o borralho dessa vida borralheira.

(MOTTA, 1996, p.98-99).

O título do poema já sugere a ideia de uma normatização do eu-lírico para evitar possíveis desavenças sociais. A ironia do autor fica evidente ao girar ${ }^{43}$ o sentido da palavra "angu", pois esta, em sentido literal, relaciona-se diretamente a um tipo de comida popular que tem como ingrediente principal farinha de milho, de mandioca ou de arroz. Entretanto, este mesmo vocábulo suscita outro sentido popular: o de bagunça, confusão, "rolo". Assim, o poeta avisa aos racistas que seu "preceituário", feito com muito esmero, é acompanhado de rebuçado (doce açucarado) "contra-receita de angu".

A condição de negro de Waldo Motta constrói uma voz lírica que necessita se pronunciar contrariamente aos valores discriminatórios ainda presentes na sociedade brasileira dita cosmopolita e civilizada. O poeta não desaparece como sujeito, visto que

\footnotetext{
${ }^{43}$ Esta palavra é empregada no sentido barthesiano, no qual a literatura teria a capacidade de "girar os saberes, não fixa, não fetichiza nenhum deles: ela lhes dá um lugar indireto, e esse indireto é precioso" (BARTHES, 2002, p. 18).
} 
sua poesia constrói imagens que denunciam o valor dado à cultura afrodescendente no Brasil e no mundo. O alerta é dado: "Quem atiça o tição/ sabe do risco que corre"; o "tição", neste contexto ambíguo, pode depreender um caráter diabólico, retomando o arquétipo de Exu, e/ou marcar a condição de negro do eu poético que está com o seu "caldeirão da paciência" transbordando.

O protesto e a luta do poeta já se verificam também na epígrafe do poema: Ogun $^{44}$, mito africano, deus da guerra, é convocado para sua causa. Esta referência coloca o discurso poético do autor em uma esfera, também, de exclusão, uma vez que a cultura religiosa do negro viveu e vive às margens das vertentes cristãs. Desde a abolição da escravatura no Brasil, em 1888, o negro se vê ainda na periferia das estruturas sociais. No entanto, em tempos atuais, as "políticas culturais da diferença" permitem um deslocamento das disposições do poder não mais alicerçados em dicotomias branco/preto, mas sim na possibilidade de repensar o branco e o preto, e não o branco ou preto, já que o ou reiteraria a exclusão.

A voz lírica do poema "Preceituário para racistas com receita de rebuçado e contra-receita de angu" revela-se engajada na luta pela cultura do negro, atentando para os riscos que o confronto entre "etnicidades" pode promover, ironizando que o "rebuçado" pode se transformar "em ração para a racinha/ ordinária dos racistas". O "braseiro" está "oculto", mas não apagado. O tom de ameaça evidencia a atitude militante de Waldo Motta, o discurso se insinua e marca o tom de protesto.

A postura literária do poeta é um desabafo em relação à discriminação operante na contemporaneidade, este é trabalhado a partir de uma linguagem inflamada e ameaçadora: "Tudo pode ficar preto/ \& vermelho, como queiram". De certa forma, o diálogo com a atualidade se encerra: o racismo opera insistentemente; a exclusão e a discriminação ainda se mantêm em outras etnicidades marginalizadas, vitimando qualquer indivíduo de cuja vida o sofrimento e a violência fazem parte.

A ideia de retorno paira sobre as contradições que envolvem as questões sociais e culturais; assombra e aterroriza o homem moderno, o qual deve sempre lutar para o reconhecimento das especificidades de cada cultura, seja erudita ou popular. Os versos de Motta ateiam fogo ${ }^{45}$ nas práticas das ideologias dominantes e colaboram para manter

\footnotetext{
44 "Ogun, o valente guerreiro,/ o homem louco dos músculos de aço!/ Ogun, que tendo água em casa,/ lava-se com sangue!" (VERGER, 1997, p. 14). O arquétipo de guerreiro é trazido para a poética de Motta, caracterizando-a como um discurso de luta e protesto.

45 "Exu é uma divindade do fogo; diz-se na África que foi ele quem trouxe o Sol" (BASTIDE, 2001, p. 162).
} 
vivas e resistentes as vozes dos indivíduos contrários aos fantasmas que ainda dividem e qualificam os homens em brancos, negros, gays, mulheres. A poesia do capixaba ressalta o quanto o percurso de marginalização social revela a face obscura da intolerância.

Outro aspecto relevante a ser destacado no poema "Preceituário para racistas com receita de rebuçado e contra-receita de angu" é a potência da voz enunciativa que, através do mito africano epigrafado, resgata a especificidade da cultura popular do negro, destacando o poder de transformação do projeto literário de Waldo Motta, já que Ogun é convocado para a guerra.

Este símbolo resgata a origem negra e marca sua diferença, deslocando, assim, as relações de poder. O negro (tição) não clama pelo Deus cristão, mas busca em divindades africanas a força para ressaltar sua diferença. Os mitos na obra Bundo $e$ outros poemas, do poeta contemporâneo Waldo Motta, cumprem o papel de dar um novo caminho para a experiência humana.

\section{REFERÊNCIAS}

AGAMBEN, G. O que é o contemporâneo e outros ensaios. Chapecó, SC: Argos, 2009.

BARTHES, R. Aula. Tradução de Leyla Perrone-Moisés. São Paulo: Cultrix, 2002.

Mitologias. Tradução de Rita Buongermino e Pedro de Souza. 11.ed. Rio de Janeiro: Bertrand Brasil, 2001.

BARCELLOS, M. C. Os Orixás e o segredo da vida: lógica, mitologia e ecologia. Rio de Janeiro: Pallas, 2002.

BASTIDE, R. O candomblé da Bahia: rito nagô. Tradução de Maria Isaura Pereira Queiroz. São Paulo: Companhia das Letras, 2001.

ELIADE, M. Mito e realidade. São Paulo: Perspectiva, 1992a.

O sagrado e o profano. Tradução de Rogério Fernandes. São Paulo: Martins Fontes, 1992b.

LEVI STRAUSS, C. Mito e significado. Tradução de António Marques Bessa. Lisboa: Edições 70, 1978.

MELETÍNSKI, E. M. Os arquétipos literários. Tradução de Aurora Fornoni Bernardini et al. Cotia, SP: Ateliê, 1998.

MOTTA, V. Enrabando o capetinha ou o dia em que Eros se fodeu. In: PEDROSA, C. (Org.). Mais poesia hoje. Rio de Janeiro: 7Letras, 2000. p. 59- 76.

Bundo e outros poemas. Campinas, SP: UNICAMP, 1996.

PRANDI, R. Mitologia dos Orixás. São Paulo: Companhia das Letras, 2001. 
SIMON, I. M. Revelação e desencanto: a poesia de Valdo Motta. Revista Novos estudos CEBRAP, São Paulo, n.70, novembro de 2004.

VERGER, P. F. Lendas africanas dos Orixás. Salvador: Corrupio, 1997.

Artigo recebido em 01/04/2011

Aceito para publicação em 29/06/2011 